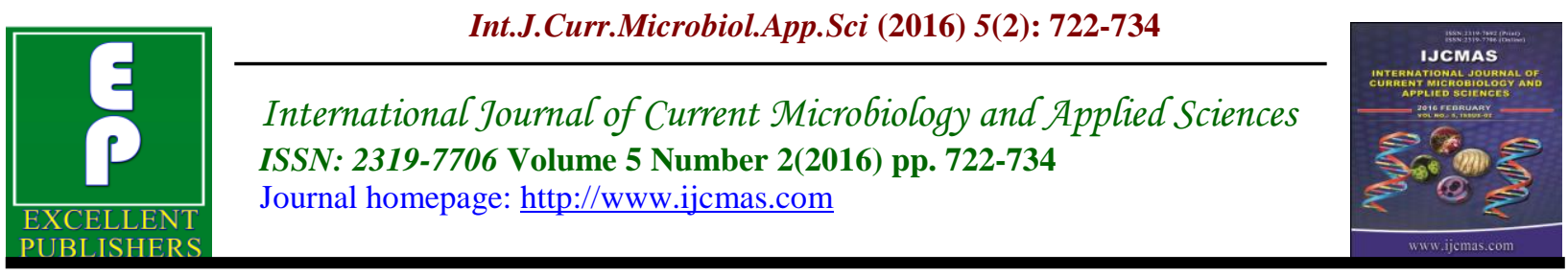

Original Research Article

doi: http://dx.doi.org/10.20546/ijcmas.2016.502.081

\title{
Analyses of Methanol Extracts of Two Marine Sponges, Spongia officinalis var. ceylonensis and Sigmadocia carnosa from Southwest Coast of India for their Bioactivities
}

\author{
K. A. Athira Krishnan ${ }^{1}$ and T. R. Keerthi ${ }^{2 *}$ \\ ${ }^{1}$ School of Biosciences, Mahatma Gandhi University, Kottayam, Kerala, India \\ ${ }^{2}$ Microbial Biotechnology Laboratory, School of Biosciences, Mahatma Gandhi University, \\ Kottayam, Kerala, India \\ *Corresponding author
}

Keywords

Sigmadocia carnosa, Spongia officinalis var. ceylonensis, Acetylcholinester ase inhibition, Anticancer activity.

\section{Article Info}

Accepted: 28 January 2016 Available Online: 10, February 2016

\section{A B S T R A C T}

Marine sponges proved to be the richest source of bioactive compounds . In this study, methanol extracts of two marine sponges, Sigmadocia carnosa and Spongia officinalis var. ceylonensis were examined for their various bioactivities. The chemical constituents of these extracts were analyzed by routine phytochemical methods showed the presence of alkaloids, phenols, steroids, triterpenoids, reducing sugars and aromatic acids in both the sponge extracts. Antioxidant activity assayed using DPPH radical scavenging activity and total antioxidant activity indicated that both sponge extracts possessed antioxidant activity. Immunomodulatory activity analyzed by calculating phagocytic index and Nitro Blue tetrazolium assay indicated that the extract of Sigmadocia was more immunomodulatory. Acetylcholinesterase inhibition assay revealed that Sigmadocia extract was more active. Anticancer effect of the methanolic extracts on colon cancer cell line HT-29 was confirmed by MTT assay. Thus the biomedical potential of the two species has been confirmed and further purification, bioactivity evaluation and chemical investigation of these extracts will yield potential bioactive molecules.

\section{Introduction}

Marine environment is a great reservoir of novel compounds with pharmacological relevance. Among 36 known living phyla, 34 of them are found in marine environment (Dhinakaran et al., 2014). Of these diverse marine organisms, marine sponges are the prolific source of bioactive molecules with novel chemical structure. Sponges- the most primitive sessile filter feeders - produce these compounds as secondary metabolites as part of chemical defense against predators, space competitors and fouling 
since they lack physical defense mechanisms. They produce a wide array of secondary metabolites ranging from derivatives of aminoacids and nucleosides to macrolides, porphyrins, terpenoids, aliphatic cyclic peroxides and sterols (Joseph \& Sujatha, 2011). According to the composition of the skeleton of the sponges, they are mainly divided into three main classes namely, Calcarea, glass sponges (Hexactinellidae) and Demosponges. Demosponges have been reported to possess large number of bioactive compounds with pharmaceutical relevance.

Bioactive compounds from sponges have been reported to possess an array of activity including anti-inflammatory, anticancer, immunosuppressive, antiviral, antibacterial and antifouling activities. In the last decade, most number of new compounds with bioactive potential has been isolated from marine sponges (Mehbub et al., 2014). At present there are a number of compounds from marine sponges which are under investigation and/ or are being developed as new pharmaceuticals.

The peninsular coast of India is a hotspot of diverse marine floral and faunal assemblages particularly sponges, sea anemones, sea cucumber, sea urchin, soft corals and diverse number of sea weeds (Sathiyanarayanan et al., 2014). In this study bioactive property of the extracts from two marine sponges of the class Demospongiae- Spongia officinalis var. ceylonensis and Sigmadocia carnosa collected from Southwest coast of India has been investigated.

Spongia officinalis var. ceylonensis confined only to the Indian seas is massive, subglobular, subpyriform in appearance with surface projections. The sponge belongs to the order Keratosida which is unique in having only spongin fibres in its skeleton.
The second species Sigmadocia carnosa belong to the order Haplosclerida having a skeleton of hydrated silica and spongin. This species bears small tubular processes bearing terminal oscules. There were reports on the antibacterial, antifungal, insecticidal and larvicidal activities of the extracts of both the species indicating that the organic extracts of these species exhibited good activity (Sujatha \& Joseph, 2011; Lakshmi \& Shukla, 2014).

\section{Materials and Methods}

\section{Sample Collection}

The marine sponge samples were collected from Southwest coast of India with the help of SCUBA divers at depth of 8-10 feet and were identified as Spongia officinalis var. ceylonensis and Sigmadocia carnosa with the help of Dr. P. A Thomas, Retd. Principal Scientist, CMFRI, Vizhinjam. The samples were kept in sterile plastic bags and transferred to lab and stored at $-20^{\circ} \mathrm{C}$.

\section{Organic Extraction}

Extraction was carried out using methanol as solvent by some modification of method of Sepcic et al., 2010. The sponge samples were lyophilized and then $1 \mathrm{~g}$ of sponge tissue was soaked in $30 \mathrm{ml}$ of methanol in sealed container and was shaken overnight at $37^{\circ} \mathrm{C}$. The extracts were filtered and remaining material was repeatedly extracted for three days at $37^{\circ} \mathrm{C}$ with constant shaking. The solvent was evaporated and the extracts were dissolved in DMSO.

\section{Screening for Chemical Constituents}

Preliminary screening for chemical constituents in the extracts was performed with slight modifications of the method of Harborne (1998). 


\section{Antioxidant Activity}

\section{Total Antioxidant Activity Assay}

The total antioxidant activities of the extracts were evaluated by the phosphomolybdenum method (Prieto et al., 1999). This assay is based on the reduction of Mo (VI) to $\mathrm{Mo}(\mathrm{V})$ by the antioxidant compound and the subsequent formation of a green phosphate / $\mathrm{Mo}(\mathrm{V})$ complex at acid $\mathrm{pH}$. A $\quad 0.3 \mathrm{~mL}$ extract solution was dispensed into screw capped test tubes. A $3 \mathrm{~mL}$ reagent solution $\left(6 \mathrm{M} \mathrm{H}_{2} \mathrm{SO}_{4}, 28 \mathrm{mM}\right.$ sodium phosphate, $4 \mathrm{mM}$ ammonium molybdate) was added and the tubes were capped and incubated at $95^{\circ} \mathrm{C}$ for 90 minutes. After cooling to room temperature, the absorbance was measured at $695 \mathrm{~nm}$ using a spectrophotometer. A blank test was done using the solvent used. The antioxidant activity was expressed as ascorbic acid equivalents using ascorbic acid as reference standard.

\section{DPPH Radical Scavenging Activity Test}

The stable 2, 2-diphenyl-1-picrylhydrazyl (DPPH) radical scavenging activity was determined using the method of Mensor $e t$ al., 2001. The samples and the reference were mixed with DPPH solution. Remaining DPPH amount was measured at $517 \mathrm{~nm}$ using spectrophotometer. Ascorbic acid was employed as the reference. Inhibition of DPPH in percentage was calculated as given below:

$\mathrm{I} \%=[(\mathrm{A}$ blank- A sample $) / \mathrm{A}$ blank $] \times 100$, where A blank is the absorbance of the control reaction and A sample is the absorbance of the extracts.

\section{Immunomodulatory Activity}

\section{Phagocytic Activity Assay}

Immunomodulatory activity was analysed by a slide method (Wadekkar et al., 2008) through in vitro phagocytosis of Saccharomyces cerevisiae. This assay was performed using blood from healthy donors and placing $100 \mu \mathrm{l}$ of it into each glass slide. The slide was incubated for the cells to get attached and then the clot was removed and the slide was flood with test sample and incubated for half an hour. The slide was then drained and flooded with a suspension of heat killed opsonised yeast cells and incubated for 1 hour. After draining the yeast suspension, slides were fixed in absolute ethanol. Then it was stained with Giemsa stain.

The phagocytic index was calculated as the number of yeast cells phagocytosed by 100 granulocytes and the percentage of phagocytosis was calculated using the equation [PI (test)-PI (control)/PI (control) $\times 100]$.

\section{NBT Assay}

The assay was performed with a modification of the method of Weiss et al., 1998. For the assay, $1 \times 10^{4}$ leucocytes/ ml were incubated with $0.1 \%$ Nitro Blue Tetrazolium dye in phosphate buffered saline (pH-7.2) and the test samples for 30 minutes at $37^{\circ} \mathrm{C}$ with $5 \% \mathrm{CO}_{2}$. A set of cells treated with crude filtrate of E.coli broth culture was used as a positive control. After incubation, a drop from each sample was carefully transferred onto a grease free glass slide and a coverslip smear was made. The smear was allowed to dry and fixed with ethanol for three minutes. Then the slides were stained with saffranin for three minutes, air dried and observed under 40X objective for calculating percentage of neutrophils with formazan granules.

\section{Acetylcholinesterase Inhibition Assay}

The acetylcholinesterase assay was 
performed according to Sepcic et al., 2010. Briefly AChE from electric eel (Sigma, USA), was dissolved in $100 \mathrm{mM}$ phosphate buffer (pH7.3) to achieve 500EU/mL. Prior to the test, the enzyme was 100 fold diluted in the same buffer. To each microtiter plate well $140 \mu \mathrm{L}$ of the Ellman reagent $(5,5-$ dithiobis-2-nitrobenzoic acid) in $25 \mathrm{mM}$ phosphate buffer $(\mathrm{pH}$ 7.0), $10 \mu \mathrm{L}$ acetylcholine (ACh) in $1 \mathrm{mM}$ final concentration, $20 \mu \mathrm{L}$ of sponge sample (aqueous or organic), and finally $50 \mu \mathrm{L}$ of AChE was added to start the reaction. Deionized $(20 \mu \mathrm{l})$ water or ethanol $(20 \mu \mathrm{l})$ was used as controls. The time course of the enzymatic reaction was monitored for 12 minutes at $412 \mathrm{~nm}$ at $25^{\circ} \mathrm{C}$.

\section{MTT Assay}

Ht-29 colon cancer cell lines were purchased from NCCS Pune were maintained in Dulbecco's modified eagles media supplemented with $10 \%$ FBS and grown to confluency at $37^{\circ} \mathrm{C}$ in $5 \% \mathrm{CO}_{2}$ in a humidified atmosphere in a $\mathrm{CO}_{2}$ incubator. The cells were trypsinized $(500 \mu 1$ of $0.025 \%$ Trypsin in PBS/ $0.5 \mathrm{mM}$ EDTA solution for 2 minutes) and passaged to $\mathrm{T}$ flasks in complete aseptic conditions. Extracts were added to grown cells at a final concentration of $6.25 \mu \mathrm{g} / \mathrm{ml}, 12.5 \mu \mathrm{g} / \mathrm{ml}, 25 \mu \mathrm{g} / \mathrm{ml}, 50$ $\mu \mathrm{g} / \mathrm{ml}$ and $100 \mu \mathrm{g} / \mathrm{ml}$ from a stock of $1 \mathrm{mg} / \mathrm{ml}$ and incubated for 24 hours. The \% difference in viability was determined by standard MTT assay after 24 hours of incubation. The cells was washed with $1 \mathrm{x}$ PBS and then added $30 \mu \mathrm{l}$ of MTT solution to the culture (MTT $-5 \mathrm{mg} / \mathrm{ml}$ dissolved in PBS). It was then incubated at $37^{\circ} \mathrm{C}$ for 3 hours. MTT was removed by washing with 1x PBS and 200ulof DMSO was added to the culture. Incubation was done at room temperature for 30 minutes until the cell got lysed and colour was obtained. The solution was transferred to centrifuge tubes and centrifuged at top speed for 2 minutes to precipitate cell debris. Optical density was read at $540 \mathrm{~nm}$ using DMSO as blank in a microplate reader. \% inhibition $=[(\mathrm{OD}$ of Control - OD of Test)/OD of Control] X 100

\section{Statistical Analysis}

The experiments were done in triplicates and error bars in graphs represents standard error of means per triplicate samples. The results were analyzed by Student's t test and were considered statistically significant when $\mathrm{p}<0.05$. IC 50 values were calculated in MS Excel.

\section{Results and Discussion}

Marine sponges are a rich source of structurally unique natural compounds, several of which have shown a wide variety of biological activities (De Rosa et al., 2003). The concentration of many highly active compounds in marine invertebrates are often minute, accounting for less than a millionth of wet weight (Proksch et al., 2002). Excellent drug candidates from sponges are often not well developed because the sponges are difficult to collect and their extraction and purification of active compound is very challenging. The sponges are naturally in close association with a variety of microorganisms and this symbiotic relation provides a rich source of biologically active secondary metabolites.

\section{Identification of Samples}

The collected samples were identified as Spongia officinalis var. ceylonensis (Fig 1A) and Sigmadocia carnosa (Fig 1B) with the help of Dr. P.A. Thomas, Retd. Principal Scientist, CMFRI, Vizhinjam, Kerala. The species Spongia used in this study is the widely used commercial bath sponge. In addition to this, Spongia officinalis has 
medicinal uses. It has been used as medicine in Israel, Syria and Lebanon and also for treatment of dry and asthmatic cough in Western world (Lev, 2003; Sipkema et al., 2005).

\section{Screening of Chemical Constituents (Table 1)}

Triterpenoids, aromatic acids, phenolics, steroids and reducing sugars were present in the extracts of the two sponge species. All these chemical constituents singly or in combination contribute to the bioactivities exhibited by the extracts. There were reports of steroids and alkaloids from methanolic extract of Spongia officinalis (Thale et al., 2002; Lakshmi \& Ghoshal, 2014). Kohamaic acids A and B are known to be constituents of Ircinia species from Okinawa (Kokubo et al., 2001). Triterpenoids such as stelletins, sodwanones, raspascionins, and sipholanols were isolated from various sponge species such as Stellata tenuis, Axinella wltneri, Raspasciona aculata and Siphonochalina siphonella respectively. All these triterpenoids exhibited cytotoxic and anticancer activity (Cimino et al., 1994). Cytotoxic activity of triterpenoids from various marine sponges has been reported (Li et al., 2013).

\section{Antioxidant Activity}

Antioxidant assays revealed that organic extracts of both the species possessed significant activity.

\section{Total Antioxidant Activity Assay}

This assay is employed for quantitative determination of antioxidant capacity through the formation of phosphomolybdenum complex. The results are expressed as $\mathrm{mg} / \mathrm{g}$ equivalence of ascorbic acid. The results (Table 2) show that methanolic extract of Spongia is more potent than that of Sigmadocia.

\section{DPPH Radical Scavenging Activity}

DPPH is characterized as a stable free radical by virtue of the delocalization of the spare electron over the molecule as a whole, so that the molecule does not dimerize, as would be the case with most other free radicals. The delocalization of electrons also gives rise to deep violet colour and absorption is measured at $517 \mathrm{~nm}$. This assay was performed for different concentrations $(62.5 \mu \mathrm{g} / \mathrm{ml}, 125 \mu \mathrm{g} / \mathrm{ml}, 250 \mu \mathrm{g} / \mathrm{ml}, 500 \mu \mathrm{g} / \mathrm{ml}$ and $1000 \mu \mathrm{g} / \mathrm{ml}$ ) of the extracts. Both the extracts exhibited significant percentage inhibition (Fig 2). IC50 values (Table 2) were calculated and it showed that Sigmadocia has very low IC50 which indicates its higher antioxidant capability.

Total antioxidant activity was more for methanol extract of Spongia than for Sigmadocia. But DPPH scavenging activity was more pronounced in methanol extract of Sigmadocia. Recent studies reported that the methanolic extract of Sigmadocia carnosa exhibited good DPPH radical scavenging activity (Joseph \& Kavimani, 2014). Extracts of Mediterranean sea sponges Dysidea avara, Axinella cannabina, Axinella damicornis, Agelas oroides and Ircinia fasciculata exhibited good DPPH activity (Aktas et al.2014). Phenolic metabolites from marine sponges have been reported to possess antioxidant activity (Utkina et al. 2004).

\section{Immunomodulatory Activity}

Immunomodulatory activities of the extracts were analysed by phagocytosis assay and Nitroblue tetrazolium reduction assay. Assays indicate that both the extracts possess immunostimulatory activity. 


\section{Phagocytic Activity}

The phagocytic index (Fig.3 and Table 3) was calculated as the number of yeast cells phagocytosed by 100 granulocytes and the percentage of phagocytosis was calculated using the equation [PI (test)-PI (control)/PI (control) $\times 100]$. The percentage of phagocytosis was greater for Sigmadocia than that of Spongia.

\section{NBT Assay}

Immunomodulatory effects of the extracts were further confirmed by NBT assay. Nitro Blue Tetrazolium is an electron acceptor used to detect indirectly the production of superoxide by stimulated neutrophils. Superoxide reduces the yellow soluble NBT to the blue black formazan, an insoluble material that precipitate which can be seen microscopically within the cell. Both the extracts exhibited significant reduction (Fig $4,5 \mathrm{~A}$ and $5 \mathrm{~B})$. The results showed that the extract of Spongia is more active.

Both the extracts possessed considerable immunomodulatory activity. Significant immunostimulant activity of methanolic extract of sponge Sigmadocia pumila was reported (Dhinakaran et al. 2012).

Table.1 Screening of Chemical Constituents

\begin{tabular}{|c|c|c|c|c|c|c|c|c|}
\hline \multirow[t]{2}{*}{ Sample } & \multicolumn{8}{|c|}{ Phytochemicals } \\
\hline & 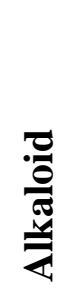 & $\begin{array}{l}0 \\
0 \\
0\end{array}$ & 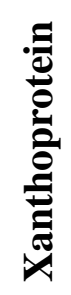 & 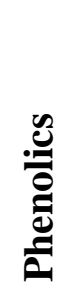 & 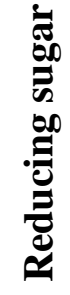 & 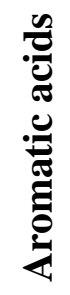 & 窇 & 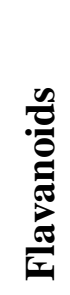 \\
\hline Spongia officinalis var. ceylonensis & - & + & - & + & + & + & + & - \\
\hline Sigmadocia carnosa & - & + & - & + & + & + & + & - \\
\hline
\end{tabular}

Table.2 Antioxidant Activity of the Extracts-Total Antioxidant Activity Expressed in Milligram Per Gram Equivalents of Ascorbic Acid. IC 50 of DPPH Radical Scavenging Activity Expressed in Microgram

\begin{tabular}{|l|l|c|}
\hline Sample & $\begin{array}{l}\text { Total antioxidant activity } \\
\text { (mg/g equivalents of } \\
\text { ascorbic acid) }\end{array}$ & $\begin{array}{l}\text { DPPH radical scavenging } \\
\text { activity assay } \\
\text { (IC50 value in } \mathbf{~ \mu g} \text { ) }\end{array}$ \\
\hline $\begin{array}{l}\text { Spongia officinalis var. ceylonensis } \\
\text { Methanol extract }\end{array}$ & $40.433 \pm 0.72188$ & 832.56 \\
\hline $\begin{array}{l}\text { Sigmadocia carnosa Methanol } \\
\text { extract }\end{array}$ & $66.33 \pm 3.38296$ & 493.49 \\
\hline
\end{tabular}


Table.3 Phagocytic Activity Phagocytic Index and Percentage of Phagocytosis were Calculated and Represented as Mean $\pm \operatorname{sem}(\mathrm{p}<0.05)$

\begin{tabular}{|l|l|l|}
\hline ample & $\begin{array}{l}\text { Phagocytic } \\
\text { index }\end{array}$ & \% of phagocytosis \\
\hline $\begin{array}{l}\text { Spongia officinalis var. } \\
\text { Ceylonensis }\end{array}$ & 1014.33 & $6.16623 \pm 0.15688$ \\
\hline Sigmadocia carnosa & 1078.66 & $10.28 \pm 0.88854$ \\
\hline
\end{tabular}

Table.4 Acetylcholinesterase Inhibitory Activity. Percentage Inhibition per Triplicate Samples were Calculated and Expressed as Mean \pm SEM . The values were Significant by Student's t-test $(\mathrm{p}<0.05)$. IC 50 values were Expressed in $\mu \mathrm{g}$

\begin{tabular}{|l|l|l|}
\hline Sample & \% inhibition & IC 50 \\
\hline Spongia officinalis var. & $22.63 \pm 1.16$ & 780.25 \\
ceylonensis & $26.39 \pm 2.15686$ & \\
& $32.83 \pm 1.09303$ & \\
& $40.67 \pm 1.20185$ & \\
& $50.33 \pm 0.88192$ & \\
\hline Sigmadocia carnosa & $27.70 \pm 0.8952$ & 667.57 \\
& $35.16 \pm 1.947$ & \\
& $37.85 \pm 1.38378$ & \\
& $47.56 \pm 1.90739$ & \\
& $58.47 \pm 1.95633$ & \\
\hline
\end{tabular}

Fig.1A Spongia Officinalis Var.Ceylonensis

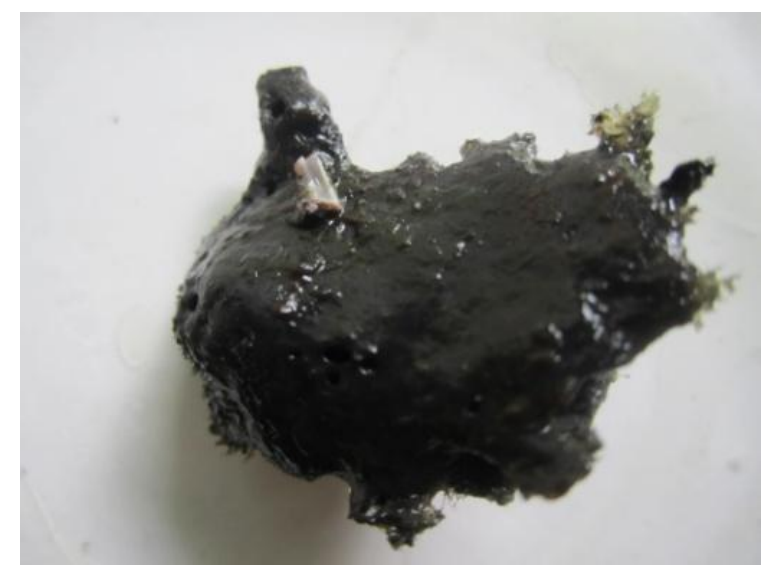


Fig.1B Sigmadocia Carnosa

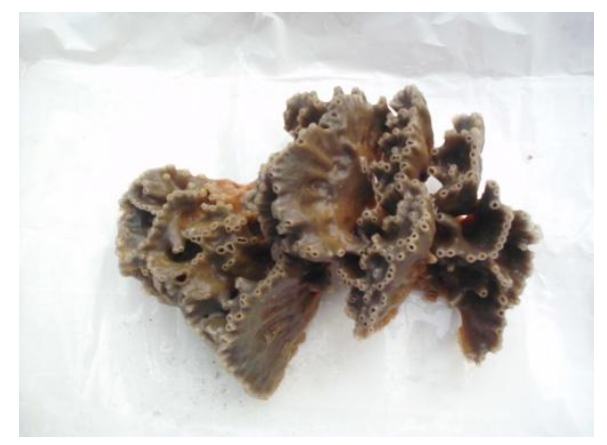

Fig.2 Dpph Radical Scavenging Activity of the Extracts. some- Spongia Officinalis var.Ceylonensis Methanol Extract; sc me- Sigmadocia Carnosa Methanol Extract.Mean \pm Standard Error from the Tested Triplicate Samples were Represented as Mean Error Bars. p value by Students Test:p<0.05

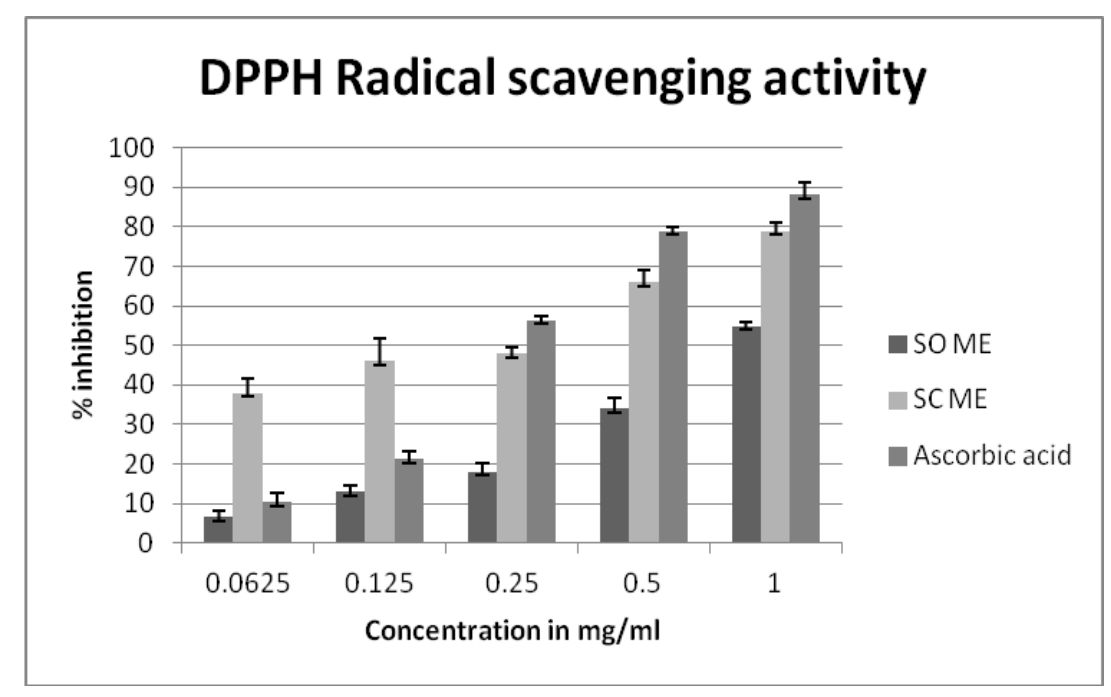

Fig.3 Phagocytic Activity by Slide Method

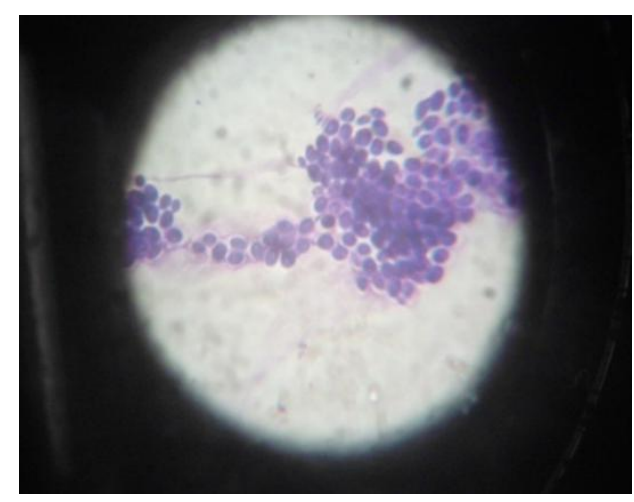


Fig.4 Nbt Reduction. Percentage of Neutrophils by Nitroblue Tetrazolium Reduction Assay Mean \pm Standard Error from the Tested Triplicate Samples were Represented as Mean Error

Bars. P value by Students Test: $p<0.05$

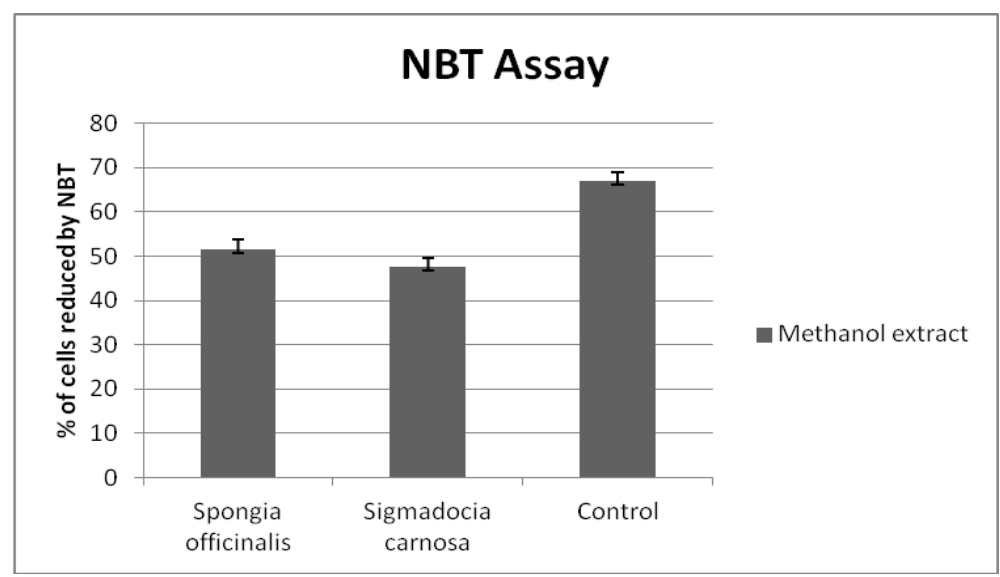

Fig.5A NBT Test

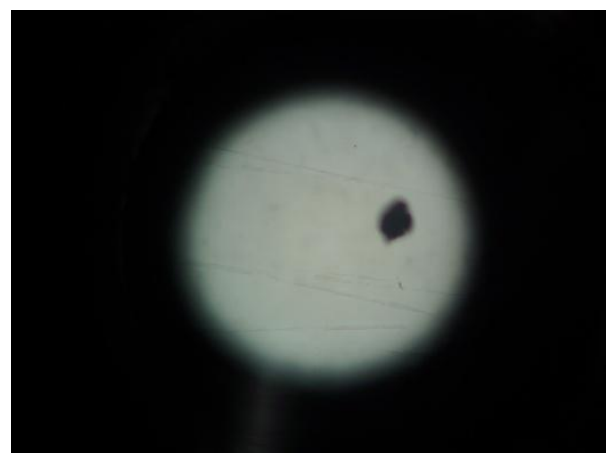

Fig.5B NBT Control

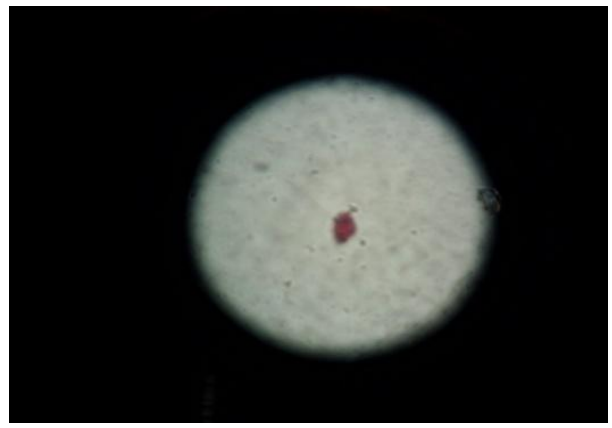


Fig.6 Acetylcholinesterase Inhibitory Activity

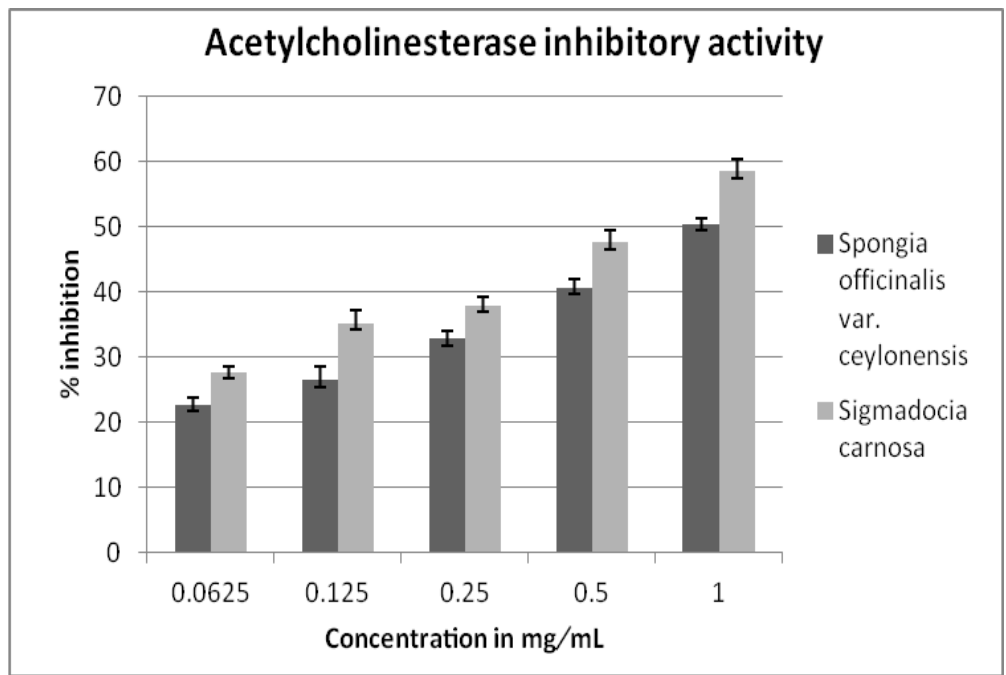

Fig.7 Mtt Assay on ht-29 Cells. Mean \pm Standard Error from the Tested Triplicate Samples were Represented as Mean Error Bars. P Value by Students Test:p<0.05

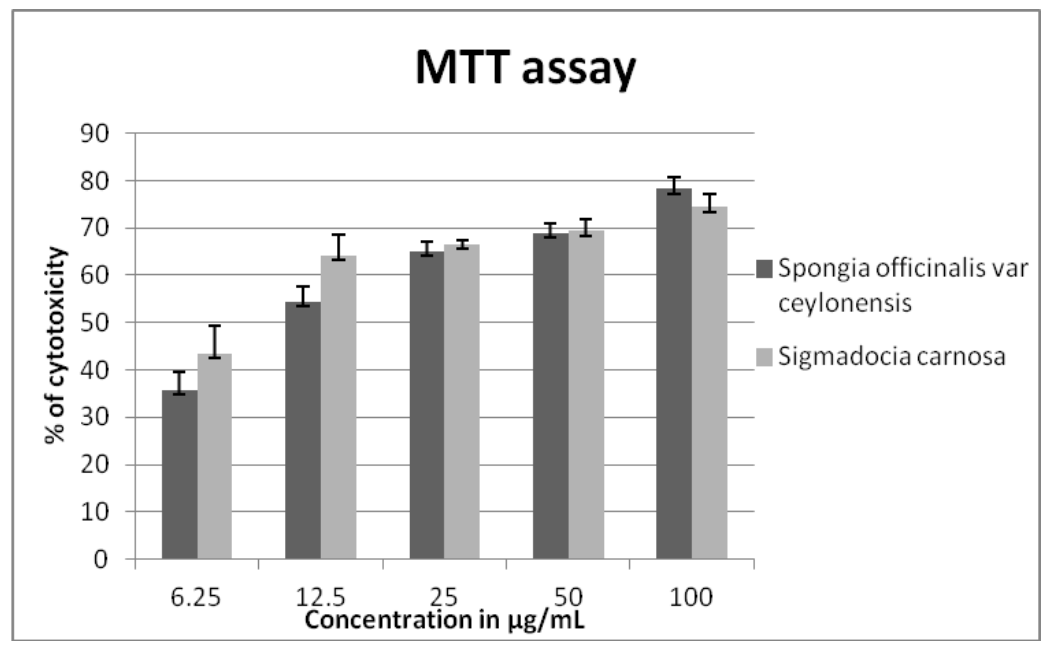

\section{Acetylcholinesterase Activity}

AChE inhibiting compounds may act as anticancer compounds affecting cholinergic system expressed in a variety of cancer cell lines. AChE inhibitors have a significant role in the treatment of Alzheimer's disease. They help in retaining the neurotransmitters especially at the synaptic terminals through the inhibition of the hydrolytic enzymes ie. cholinesterases thereby compensating the deficiency of the cholinergic neurotransmitters in AD patients (Langjae et al, 2007).

The extracts of both the sponges exhibited significant percentage inhibition (Table 4 and Fig 6). IC 50 values and percentage inhibition indicated that Sigmadocia was more active. Methanolic extract of Sigmadocia showed a low IC 50 value of 684.36 $\mu \mathrm{g}$. AChE inhibitory activity 
exhibited by both the extracts indicate that these extract may serve as good candidates for development of drugs against cancer and Alzheimer's disease since AChE inhibitors act on cholinergic system. Acetone, butanol and methanolic extracts of marine sponge Agelas clathrodes exhibited substantial AChE inhibitory activity (Sepcic, 2010). Methanolic extracts of Ircinia and Dysidea species displayed promising results in $\mathrm{AChE}$ inhibition test over 50\% (Aktas et al., 2014). Steroidal alkaloid from purified methanol fractions of Corticium species exhibited potent AChE activity (Langjae et al., 2007).

\section{MTT Assay}

The potent methanolic extracts subjected to MTT assay against HT-29 cells significantly reduced cell viability (Fig 6). The extracts exhibited $35-78 \%$ inhibition and the activity is concentration dependent. Methanolic extract of Spongia has an IC 50 value of $15.11 \mu \mathrm{g}$ and Sigmadocia with an IC 50 value of $14.08 \mu \mathrm{g}$, indicated that both species would be good candidates for anticancer drug development. Anticancer activity by MTT assay of ethyl acetate extract of marine sponge, Aurora globostellata from Tuticorin coast have been reported (Chairman and Singh, 2013).

This study confirmed the medical potential of the two species. Though many reports were there on the antibacterial, antifungal, larvicidal and insecticidal activities of these two species, reports on antioxidant and anticholinesterase activities were scanty. This is the first report on the antioxidant, anticholinesterase and anticancer activities of the two species from the Southwest coast of India.

In conclusion, Sessile marine invertebrates such as sponges lack physical defense mechanism and hence they produce a variety of secondary metabolites as part of their chemical defense system - active immune mechanism in sponges. So it is not an astonishing fact that they produce potent antioxidant, cytotoxic and antibacterial compounds. The marine sponges have already proved to be the most important source of novel molecules with pharmacological properties. The bioactivity shown by sponges may be mainly due to the chemicals present in the sponge and its symbiotic microorganisms. But the secondary metabolites produced as part of defense may vary from species to species.

The results indicate that the extracts of both the sponge species possess significant bioactivity. This activity may be mainly due to the various chemical constituents present in the extracts which were revealed by chemical analysis. So it is expected that the purification and bioanalysis of these extracts will yield potent active compounds. Thus it was confirmed that further bioassay guided fractionation of these extracts and purification of them would provide compounds which can be used as novel drug candidates.

\section{Acknowledgement}

The authors would like to express our sincere gratitude to Dr. P. A. Thomas, Retd. Principal Scientist, CMFRI, Vizhinjam and the DBT-SERB instrumentation facility for providing us the technical support. This work was financially supported by the DSTINSPIRE [IF120633].

\section{References}

Aktas, N. Gene, Y. Gozcelioglu, B. Konuklugil, B. (2013). Radical scavenging effect of different marine sponges from Mediterranean coasts. Rec. Nat. Prod., 7(2): 96-104. 
Chairman, K. and Singh, A.J.A.R. (2013).Cytotoxic activity of sponge extract and cancer cell line from marine sponges. Biomaterial and Biomedicine, 2(1):1-5.

Cimino, G. Mondaio, A. Trivelline, E. (1994). Minor triterpenoids from the Mediterranean sponge Raspasciona aculeate. J. Nat. Prod., 57:784-790.

De Rosa, S. Mitova, M. Tommonero, G. (2000). Marine bacteria associated with sponge as a source of cyclic peptides. Biomol. Eng., 20:311-316.

Dhinakaran, D.I. Lipton, A.P. (2012). Evaluation of bioactivity in marine sponge Sigmadocia pumila collected from the South Eastern region of India. J. Microbiol. Biotech. Res., 2(5): 651-656.

Dhinakaran, D.I. Sivakumar, T. Lipton, A.P. (2014). Detection of marine derived natural products synthesized in marine sponges collected from Tuticorin, India. European Journal of Biological Sciences, 6(1): 01-06.

El-Marsy, H.A. Fahny, H.H. Abdelwahed, A.S.H. (2000).Synthesis and antimicrobial activity of some new benzimidazole derivatives. Molecules. 5:1425-1438.

Harborne, J. B. (1998). Phytochemical Methods: A guide to modern techniques of plant analysis, $2^{\text {nd }}$ edition, London, Chapman and Hall. 54-84.

Joseph, B. Sujatha, S. (2011). Pharmacologically important natural products from marine sponges. Journal of Natural Products, 4: 0512.

Joseph, V. Kavimani, S. (2014). Evaluation of apoptosis regulating efficacy of chosen marine

sponge extracts. Asian Journal of Biomedical and Pharmaceutical Sciences, 4(30): 50-55.
Kokubo, S. Yogi, K. Inuzuka, T. Suenaga, K. Ueda, K. Uemura, D. (2001). Kohamaic acids and B, Novel cytotoxic sesterterpenic acids, from the marine sponge, Ircinia sp. Chem Lett., 176-177.

Lakhsmi, V. Ghoshal, S. (2014). Antiamoebic activity of marine sponge Spongia officinalis var ceylonensis Dendy. Pharmaceutical Journal, 17(1):38-42.

Lakshmi, V. Shukla, P. K. (2014). Antimicrobial activity of marine sponge Spongia officinalis var. ceylonensis, Dendy. J. Mar. Biol. Oceanogr., 3: 3.

Langjae, R. Bussarawit, S. Yuenyongsawad, S. Ingkaninan, K. Plubrukarn, A. (2007). Acetylcholinesterase inhibiting steroidal alkaloid from the sponge Corticium sp. Steroids, 72:682-685.

Lev, E. (2003). Traditional healing with animals (zootherapy) medieval to present day- Levantine practice. Journal of Ethnopharmacology, 85:107-118.

Li, Y-X. Himaya, S.W.A. Kim, K. S. (2013). Triterpenoids of marine origin as anticancer agents. Molecules, 18:7886-7909.

Mehbub, M.H. Lei, J. Franco, C. Weizhang. (2014). Marine sponge derived natural products between 2001 and 2010: Trends and Opportunities for discovery of Bioactives, Mar. Drugs., 12:4539-4577.

Mensor, L. L. Menezer, F. S. Leitao, G. G. Reis, F. S. Santos, T. C. Coube, C. S. Leitao, S.G. (2001).Screening of Brazilian plant extracts for antioxidant activity by the use of DPPH free radical method. Phytother. Res., 15: 127-130.

Prieto, P. Pineda, M. Aguilar, M. (1999). Spectrophotometric Quantitation of 
antioxidant capacity through the formation of a phosphomolybdenum complex: Specific application to the determination of Vitamin E, Anal. Biochem., 269:337-341.

Proksch, P. Ediada, P.A., Ebel, R. (2002). Drugs from the seas-current status and microbiological implications. Appl. Microbiol. Biotechnol., 59:125-134.

Sathiyanarayanan, G. Gandhimathi, R. Sabarathnam, B. Seghalkiran, G. Selvin, J. (2014). Optimization and production of pyrrolidone antimicrobial agent from marine sponge associated Streptomyces sp. MAPS15. Bioprocess. Biosyst. Eng., 37: 567-573.

Sepcic, K. Kauferstein, S. Mebs, D. Turk, T. (2010). Biological activities of aqueous and organic extracts from tropical marine sponges. Mar. Drugs., 8(5):1550-1566.

Sipkema, D. Franssen, M.C.R. Osinga, R. Tramper, J. Wijffels, R.H. (2005). Marine sponges as pharmacy. Marine Biotechnology., 7:142-162.

Thale, Z. Johnson, T. Tenney, K. Wenzel, P.
J. Lobkovsky, E. Clardy, J. Media, J. Pielraszkiewicz, H. Valerioti, F.A. Ctews, P. (2002). Structures and cytotoxic properties of sponge derived biannulated acridines. J. Org. Chem., 67: 9384-9391.

Utkina, N. K. Makarchenbo, A. E. Slachdokova, D.V. Virovaya, M.V. (2004). Antioxidant Activity of phenolic metabolites from marine sponges. Chemistry of Natural Compounds., 40: 4.

Wadekkar, R. R. Agarwal, S. V. Tewari, K. M. Shinde, R. D. Mate, S. Patil, K. (2008). Effect of Baliospermum montanum root extract on phagocytosis by human neutrophils, International Journal of Green Pharmacy, 2(1): 46-50.

Weiss, T. Eckstein, H. Weiss, C. Dichm, C. (1998). Neutrophil function in peripheral arterial occlusive disease: the effects of prostaglandin E1. Vascular medicine, 3:171-175.

\section{How to cite this article:}

Athira Krishnan, K. A., and Keerthi, T. R. 2016. Analyses of Methanol Extracts of Two Marine Sponges, Spongia officinalis var. ceylonensis and Sigmadocia carnosa from Southwest Coast of India for their Bioactivities. Int.J.Curr.Microbiol.App.Sci.5(2): 722-734. doi: http://dx.doi.org/10.20546/ijcmas.2016.502.081 